\title{
Production of red tilapia (Oreochromis spp.) in floating cages in the Mekong Delta, Vietnam: mortality and health management
}

\author{
Annette S. Boerlage ${ }^{1}$, Tu Thanh Dung ${ }^{2}$, Tran Thi Tuyet Hoa ${ }^{2}$, Jeffrey Davidson ${ }^{1}$, \\ Henrik Stryhn ${ }^{1}$, K. Larry Hammell ${ }^{1, *}$ \\ ${ }^{1}$ Department of Health Management and Centre for Veterinary Epidemiologic Research (CVER), Atlantic Veterinary College, \\ University of Prince Edward Island, 550 University Avenue, Charlottetown, PEI C1A 4P3, Canada \\ ${ }^{2}$ Department of Aquatic Pathology, College of Aquaculture and Fisheries, Can Tho University, Campus II, 3/2 street, \\ Ninh Kieu district, Can Tho city, Vietnam
}

\begin{abstract}
The Mekong Delta in Vietnam is one of the most productive aquaculture regions in the world, in which the red tilapia (Oreochromis spp.) industry is a small-scale industry that mainly supplies local markets in the delta region. Little is known about the frequency of mortality events and health management in this sector. We describe red tilapia floating cage production systems in the Mekong Delta, Vietnam, for the purposes of quantifying mortality and associated production factors, and describing practices that may influence pathogen introduction and spread to and from farms. In July 2014, approximately 50 red tilapia farmers from 4 provinces ( 201 farmers in total) were randomly selected and interviewed. Median overall perceived mortality (PM) within a production cycle was $35 \%$. Overall PM was found to be affected by province $(\mathrm{p}<0.01)$, age of farmers $(p=0.01)$, anticipated main reason for PM in the first 2 wk $(p=0.03)$, most common market for the fish $(p=0.02)$, and whether farmers recorded stocking information $(p=0.01)$. Based on the interviews, we describe and discuss processes that potentially affect pathogen introduction and spread on these farms, such as movements of live and dead fish, distances between farms, mechanical transmission, and biosecurity practices such as treating fish before stocking, using disinfectants, and sharing equipment, and harvesters' movements. This study provides fundamental understanding of red tilapia aquaculture management in the Mekong Delta, and describes management factors that could become important in the event of disease outbreaks.
\end{abstract}

KEY WORDS: Production characteristics · Questionnaire · Aquaculture · Multivariable analysis · Perceived mortality

\section{INTRODUCTION}

Tilapia farming is the most widespread type of aquaculture in the world, with production reported in at least 135 countries and territories on all continents (FAO 2014). Tilapia are popular fish for culture because of their hardiness, breeding success, short grow-out cycles, tolerance to a wide range of environmental factors, including fresh and brackish water, resistance to disease, easy handling, and appealing flavor (El-Sayed 2006, Silva et al. 2006).

${ }^{*}$ Corresponding author: lhammell@upei.ca
Over $90 \%$ of farmed tilapia are produced in developing countries, mainly in Asia (El-Sayed 2006). The 2 main cultured tilapia species in Asia are Nile tilapia Oreochromis niloticus and red tilapia (Oreochromis spp.), a hybrid between $O$. mossambicus and $O$. niloticus (Romana-Eguia et al. 2004, Abdelhadi 2011). Red tilapia are suitable for intensive and extensive conditions and have high consumer acceptance in several Asian countries because of their resemblance to premium marine species (Gupta \& Acosta 2004).

(C) The authors 2017. Open Access under Creative Commons by Attribution Licence. Use, distribution and reproduction are unrestricted. Authors and original publication must be credited. 
The Mekong Delta in Vietnam is one of the most productive aquaculture areas in the world (Nguyen \& $\mathrm{Tu}$ 2013). The majority of commercially produced aquatic species in the delta are striped catfish Pangasianodon hypophthalmus and penaeid shrimp (Penaeus monodon and Litopenaeus vannamei) (De Silva \& Phillips 2007, Phuong \& Oanh 2010, De Silva \& Phuong 2011). Tilapia products are mainly destined for local consumption and have contributed substantially to livelihoods, food supply, and poverty alleviation (Hung 2010, Nguyen \& Vo 2011). However, during the last $10 \mathrm{yr}$, export of tilapia has increased from 8 to 68 markets that are mainly in the USA, Colombia, and the EU (VASEP 2016b).

In 2015, an area of approximately 25400 ha was used for tilapia culture in Vietnam, leading to close to 182000 t of product (VASEP 2016a). Red tilapia in the Mekong Delta are mainly cultured in wooden cages that float in series parallel to the river banks (VASEP 2016a), similar to methods in other Southeast Asian countries including Indonesia, Thailand, Malaysia, and Singapore (Gupta \& Acosta 2004, De Silva \& Phillips 2007). Advantages of cage culture over other culturing methods, such as culture ponds or raceways, include a relative low capital investment, low operating costs, and flexibility of management (Gupta \& Acosta 2004). In the tributaries of the Mekong Delta, concentrated collections of small-scale cagecultured farms share the benefits of services such as harvesters and food delivery (Fig. 1).

Disease is a primary constraint to aquaculture (Bondad-Reantaso et al. 2005). In the Mekong Delta, disease has led to major financial losses in important aquaculture sectors, such as shrimp and catfish (De
Silva \& Phuong 2011, Leaño \& Mohan 2012, Lightner et al. 2013). However, disease does not only affect the larger sectors. The often resource-poor farmers in smaller-scale industries, such as the red tilapia cageculture, are also at risk of experiencing major impacts on livelihoods by disease outbreaks, as these lead to losses of production, income, and assets (Arthur et al. 2002).

In aquaculture, disease is the result of complex interactions between pathogens, environmental factors, host condition, husbandry practices, and management practices (Subasinghe 2005). As a result, improving disease management in an aquaculture sector requires insight into multiple processes affecting diseases and their interactions, and a thorough insight into health management on farms and the sector in general. Examples of practices that affect disease and are common in the aquaculture industry are trade of live fish, introduction of fry and fingerlings, live fish harvests, ineffective biosecurity measures, and delayed awareness of emerging diseases (Bondad-Reantaso et al. 2005). One way to improve health management is to understand the production system events and possible risks and pathways for pathogen transmission, and to identify interventions that may lead to improvements in the health status of fish (Subasinghe 2005). Surveillance to identify the distribution of disease and its socio-economic impacts requires knowledge of risk pathways and the potential to introduce biosecurity barriers for minimizing their influence.

To our knowledge, there is no description of the red tilapia sector in the Mekong Delta. Therefore, the first objective of this pilot study was to (1) describe
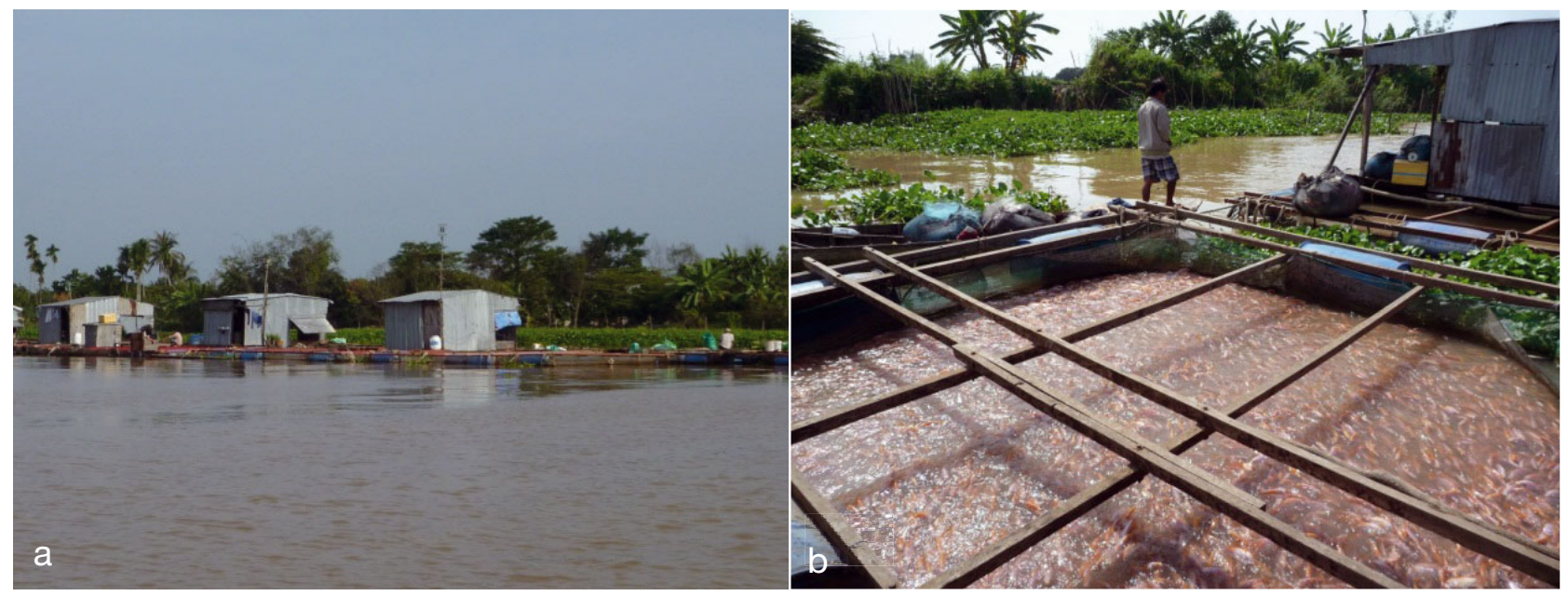

Fig. 1. Red tilapia (Oreochromis spp.) cage culture in the Mekong Delta, Vietnam: (a) farms that float in strings along the river bank, (b) wooden cages 


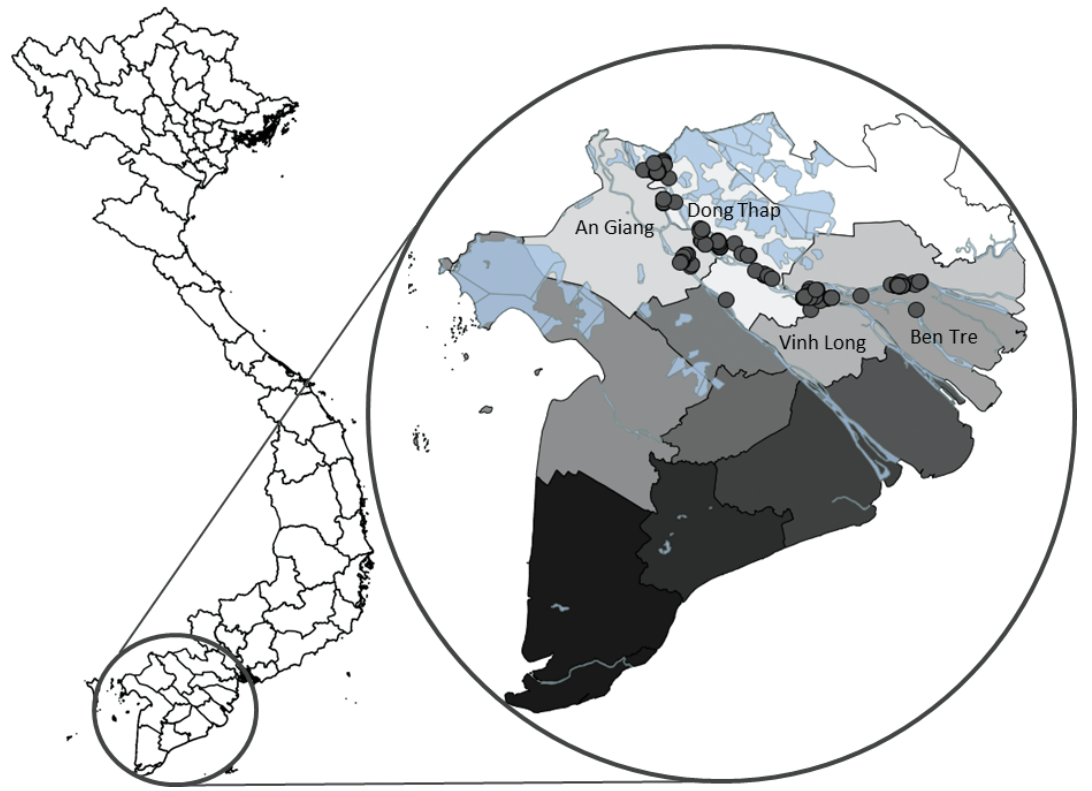

Fig. 2. Study area in the Mekong Delta, Vietnam. Farms participating in the questionnaire are indicated with dots, and provinces in which the study took place are labeled. Major rivers, water bodies, and wetlands are indicated with blue lines; provinces are shown in different shades of gray

provinces, for a total of 201 completed questionnaires. Farms were randomly selected from a database provided by the local authorities for the provinces of Vinh Long (51/149 tilapia farms), An Giang (50/375), Dong Thap (50/ 549), and Ben Tre (50/95; Fig. 2). Local government authorities and farmers were asked for cooperation prior to the questionnaire, and received a compensation fee for participation. If the selected farmer did not want to cooperate or was not home, a neighboring farm was approached instead.

\section{Data management for descriptive univariate analysis}

Results on paper records were entered in the computer program EpiData3.1 (Lauritsen \& Bruus 2016). Data verification and analysis were carried out using STATA14.0 (Stata-

red tilapia floating cage production systems in the Mekong Delta, Vietnam, and factors that may contribute to disease outbreaks. Building upon this description, further objectives were to (2) quantify mortality and associated production factors; and (3) describe practices potentially influencing introduction and spread of pathogens to and from farms.

\section{MATERIALS AND METHODS}

\section{Questionnaire design}

The study area consisted of 4 provinces in the Mekong Delta, southern Vietnam (Fig. 2), where most red tilapia is farmed. Based on a pilot interview with 2 farmers, a questionnaire was designed with 225 questions that were either open-ended or limited choice. Farm-level questions addressed farmer and employee characteristics, cage preparation, site history, animal population(s) on site, distance to other sites, production process, harvesting, information recording, and fish diseases. Cage-level questions covered stocking, fish movement, treatment of fish, and feeding. A pre-test was done with 4 farmers, and questions were adjusted to improve understanding and precision. The questionnaire was conducted by face-to-face interviews in July 2014 on approximately 50 small-scale tilapia cage farms in each of the 4
Corp 2015). An overview of data handling and analysis is provided in Fig. 3. Answers to the 225 questions on each survey were individually evaluated, standardized, split, and categorized. Questions that were never or rarely ( $<10$ farmers) answered by farmers, and open questions that could not be categorized, were dropped, as were indicator variables (e.g. identification number, farmer's telephone number, farmer's name, farm coordinates). A total of 99 variables remained, of which 17 related to 'mortality' (see Table S1 in the Supplement at www.int-res.com/ articles/suppl/d124p131_supp.pdf), and the remaining 82 variables were divided into 7 groups: 'general and farmer' (11 variables; Table S2A); 'human consumption of fish' ( 8 ; Table S2B); 'site and employment' (20; Table S2C); 'fallow and stocking' (9; Table S2D); 'between stocking and harvest' (11; Table S2E); 'harvest' (15; Table S2F); and 'record keeping' (8; Table S2G). These variables were further standardized and re-categorized as required, e.g. categorical answers were merged to other categories when possible if fewer than 10 answers were obtained in a single category. For example, the question 'if a cage is partly harvested, do you mix remaining fish with other cages' had a range of 5 answers, of which 'usually, $20-80 \%$ of the time' was combined with 'sometimes, $1-20 \%$ of the time', because only 4 and $6 \%$ of farmers, respectively, answered in these categories (Table S1). 


\begin{tabular}{|c|c|c|}
\hline Survey responses: 225 questions & \multicolumn{2}{|l|}{120 farmers responded } \\
\hline & \multicolumn{2}{|l|}{$\nabla$} \\
\hline Data management for descriptive univariate analysis & \multicolumn{2}{|c|}{$\begin{array}{l}\text { Removed potential predictor (question) if } \\
\cdot<10 \text { farmers answered } \\
\text { - open questions that could not be categorized } \\
\text { - Questions were indicators, e.g. name of farmer }\end{array}$} \\
\hline \multicolumn{3}{|c|}{$\nabla$} \\
\hline Descriptive univariate analysis with 99 potential predictors & $\begin{array}{l}\text { Potential predictors divided into } 8 \text { groups } \\
\text { - mortality (17) } \\
\text { - general and farmer (11) } \\
\text { - human consumption of fish (8) } \\
\text { - site and employment (20) } \\
\text { - fallow and stocking (9) } \\
\text { - between stocking and harvest (11) } \\
\text { - harvest (15) } \\
\text { - record keeping (8) }\end{array}$ & $\begin{array}{l}\text { 'Results' section } \\
\text { Supplement, } \\
\text { Table S1 } \\
\text { Supplement, } \\
\text { Table S2 }\end{array}$ \\
\hline \multicolumn{3}{|c|}{$\nabla$} \\
\hline Adjust potential predictors when needed & \multicolumn{2}{|c|}{ Categorical answers merged if $<10$ answers in a single category } \\
\hline & \multicolumn{2}{|l|}{$\gamma$} \\
\hline Data management for factor analysis & \multicolumn{2}{|c|}{$\begin{array}{l}\text { Removed potential predictors if } \\
\cdot<120 \text { responses } \\
\text { - dichotomous predictors with }<10 \text { answers in one category } \\
\text { Transformed potential predictors if } \\
\text { - nominal categorical predictors }\end{array}$} \\
\hline & \multicolumn{2}{|l|}{$\nabla$} \\
\hline Univariate associations: 81 predictors, of which 45 with $P<0.3$ & \multicolumn{2}{|l|}{ Divided over 8 groups (see univariate analysis) } \\
\hline & \multicolumn{2}{|c|}{$\nabla$} \\
\hline Factor analysis: 8 FAs, one per group, using the 45 predictors & \multicolumn{2}{|l|}{ Reduced to at most 3 factors per group } \\
\hline $\begin{array}{l}\text { Backwards stepwise linear multivariable regression } \\
\text { using all predictors determined by the } 8 \text { FAs }\end{array}$ & Representing all 8 groups & 'Results' section \\
\hline
\end{tabular}

Fig. 3. Overview of methods

\section{Perceived mortality (PM)}

Previous communication with farmers showed that most farmers do not record mortality, stocking numbers, or harvest numbers. Therefore, farmers were asked: 'What do you consider normal mortality on your farm?' and we refer to their answers as perceived mortality (PM). Answers for PM were provided in categories of $10 \%$ increments (0-10 up to 91-100\%) (Fig. 4). For data analysis, these intervals were quantitatively represented by their midpoint values (i.e. 5 up to $95 \%$ ). Two PMs are described in this study: PM between stocking and harvesting is referred to as 'overall PM,' which is the study outcome; PM during the first $2 \mathrm{wk}$ is used as a predictor in the model. Other questions for which we used abbreviations are: 'main reasons for initial mortality' (RIM), and 'main reasons for overall mortality' (ROM).

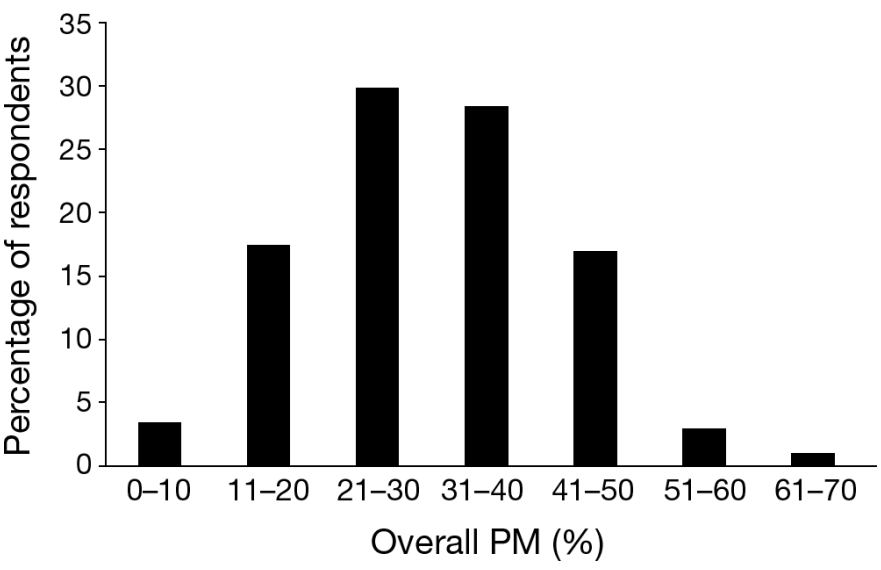

Fig. 4. Distribution of overall perceived mortality (PM) in farmed red tilapia (Oreochromis spp.) ( $\mathrm{n}=201$ farmers interviewed) 


\section{Data preparation for multivariable analysis}

First, all variables with $<120$ responses $(\sim 60 \%$ response rate) were discarded as potential predictors (i.e. original or adjusted variables entering the analysis). Second, because factor analysis does not allow for categorical predictors, nominal categorical predictors were transformed into indicators of individual categories. Third, dichotomous potential predictors with fewer than 10 answers in 1 category were discarded. In total, 81 potential predictors remained. For these potential predictors, linearity between continuous predictors and the outcome was assessed, and predictors were transformed appropriately, using log transformation or other fractional polynomials. Relations of individual predictors to the outcome were assessed using the F-statistic in linear regression. A total of 45 predictors with univariate associations with $\mathrm{p}<0.3$ were carried on to the next step of the analysis.

\section{Factor analysis of predictors}

Within each of the previously described 8 groups, we used factor analysis to reduce the predictor information to be carried forward to the multivariable analysis. Generally speaking, this method makes it possible to describe a set of variables in terms of a smaller number of factors. In the process, it also provides a better understanding of the relationship between variables in a group (Boklund et al. 2004, Manly 2004, Joffre \& Bosma 2009). The factor analysis was based on the polychoric correlation matrix because of the presence of many indicator variables among the variables (Kolenikov \& Angeles 2004). We used $75 \%$ of variation explained as the cut-off, which led to at most 3 factors in the groups. Varimax rotation was used to increase interpretability of the 3 factors. If a resulting factor essentially agreed with an existing predictor, this predictor was carried forward to the multivariable analysis; otherwise, predictors were redefined or merged as appropriate or new predictors were constructed based on the factor analysis.

\section{Multivariable analysis}

The final multivariable model was obtained using backward stepwise linear regression (at a significance level of 0.05) from the set-up of predictors determined in the 8 factor analyses, including 'age of the farmer,' which was considered a potential confounder. Predicted means were computed for average year of birth and for all other predictors at their observed distributions. Differences within categorical predictors were calculated using pairwise comparisons with Bonferroni adjustments. The model assumptions were evaluated using standardized residuals, and the need for transformation of the outcome was explored through a Box-Cox analysis. As a sensitivity analysis, the final multivariable model was also estimated using interval regression, avoiding representing the PM intervals by the interval midpoints.

\section{Practices potentially influencing introduction and spread of pathogens}

Questions involving husbandry factors that potentially influence introduction or spread of pathogens at the site level were grouped according to an adaptation of the risk themes used for other fish farms (Oidtmann et al. 2011). In that study, aquatic animal disease specialists, aquatic disease epidemiologists, fish farmers, fish health inspectorate representatives, private veterinarians who provide service to fish farms, private fish health professionals, and representatives of the Competent Authorities were consulted to identify routes of pathogen introduction and spread of diseases listed in EC Directive 2006/88. We used the categories 'live fish movement,' 'dead and harvested fish movement,' 'environmental factors,' and 'mechanical transmission and biosecurity practices' (see Fig. 6).

\section{RESULTS}

\section{Survey results}

The exact questionnaire questions, corresponding answers, percent of responses, and corresponding average PM can be found in Supplement Tables S1 \& S2. Values represent medians unless specified otherwise.

Farmer characteristics and habits regarding aquaculture products

Nearly all interviewees owned their farms and lived on site most of the time. The majority of interviewees were male, with women representing $10 \%$ of the group. Median age was $42 \mathrm{yr}$, ranging from 23 to $87 \mathrm{yr}$ of age. In Vinh Long, about one-third of the farmers owned a second site, whereas in Ben Tre 
province, only 1 farmer owned a second site. Roughly three-quarters of the farmers who owned more than 1 site shared equipment between sites. About onethird of the farmers had full-time employees, and $12 \%$ of farmers used part-time workers.

Most farmers consumed red tilapia from their own sites. Almost as many farmers also consumed fish bought at local markets, mainly catfish Pagasianodon hypophthalmus, snake head Channa striata, and climbing perch Anabas testudineus. About threequarters of the farmers consumed fish caught within $500 \mathrm{~m}$ of the farm, mostly local catfish species, but also including a range of other species, such as common carp Cyprinus carpio and snakehead. Half of the farmers discarded fish parts that they did not consume directly into the river. Less frequently, discarded fish parts were fed to fish, dogs, or other animals on the farm, or used as garden fertilizer.

\section{Site characteristics}

Although the rivers in the Mekong Delta can be brackish near the ocean and tilapia are tolerant to salinity (Gupta \& Acosta 2004), nearly all sites in the study were located in primarily fresh water. Each site had a median of 3 cages; the largest farm had 19. Cages were $10 \times 5 \times 3.5 \mathrm{~m}\left(175 \mathrm{~m}^{3}\right)$, containing about 16000 fish at the time of the interview (ranging from 1000 to 2000000 ). The median density of fish was calculated to be 175 fish $\mathrm{m}^{-3}$. Farmers produced 2 (maximum 4) crops of red tilapia $\mathrm{yr}^{-1}$ cage $^{-1}$, with 1 crop taking about 5.5 mo. Red tilapia culture on surveyed sites was ongoing for $4 \mathrm{yr}$ (maximum $7 \mathrm{yr}$ ) at the time of the survey. In addition to red tilapia aquaculture, $10 \%$ of farmers owned ponds in which they cultured striped catfish. About one-fifth of the farmers included agriculture at their sites in the form of an orchard, rice production, or a small vegetable garden. Two-thirds of the farmers had dogs on their farms, and some farmers reported the presence of wild birds and rodents, such as mice and rats.

The median distances to nearest upstream and downstream farms were, respectively, 20 and $10 \mathrm{~m}$. The farms were about $4 \mathrm{~km}$ away from upstream cities, the maximum distance being $80 \mathrm{~km}$.

\section{Production characteristics}

Before stocking new fish in a cage, most farmers fallowed the cage (i.e. kept the cage empty between harvest and stocking) for 1 to $7 \mathrm{~d}$. More than half of the farmers always cleaned nets before introducing new fish, but $3 \%$ of farmers never cleaned nets before restocking. Most farmers (82\%) treated fish before stocking. The majority of those (98\%) bathed fish in salt, $\mathrm{KMnO}_{4}, \mathrm{CuSO}_{4}$, or iodine to treat fry or fingerlings before stocking, but none of the fish were vaccinated prior to stocking. A quarter of the farmers recorded the numbers of fish stocked in record books or, for a small minority, on loose paper. Stocking of fish (median $4 \mathrm{~g}$, ranging from 1 to $10 \mathrm{~g}$ ) occurred year round, with $60 \%$ of farmers stocking in the dry season and $40 \%$ in the wet season. The majority of fish originated from the same province, and about one-quarter of the fish were from elsewhere in the Mekong Delta. A few farmers produced their own fingerlings.

Fish were cultured for 5 to 6 mo before harvest; the minimum and maximum reported durations were 2 and $10 \mathrm{mo}$, respectively. During that period, the majority of farmers never mixed fish that were stocked at different times, although fish movement between sites did occur. All farmers fed pellets 2 to 3 times each day. None of the farmers recorded environmental parameters like $\mathrm{pH}$, salinity, or water temperature.

Median harvest weight of fish was estimated to be $700 \mathrm{~g}$, ranging from 250 to $1500 \mathrm{~g}$. Farmers decided to harvest, in most cases, when the price of fish was appealing. Harvesting a cage usually took $2 \mathrm{~d}$, but ranged between 1 and $35 \mathrm{~d}$. Two-thirds of the farmers indicated that only part of a cage was harvested at a time. After harvest, about one-third of the farmers mixed fish in a partly harvested cage with other fish already at the site. The majority of harvests were handled by an intermediate buyer who, according to $88 \%$ of the farmers, visited more than 1 farm per day when harvesting. Half of the farmers indicated that nets used for harvesting were owned by the intermediate buyer, while the other half of the farmers used their own nets. Three-quarters of the farmers indicated that the intermediate buyer did not use disinfectants before entering the farm for harvesting. Only $13 \%$ of farmers recorded harvest information in a book or on loose paper. Farmers indicated that fish were sold to domestic markets inside and outside the Mekong Delta in about equal proportions, and, to a lesser extent, to the local community, and nearly all fish were transported live.

\section{Mortality characteristics}

Nearly all farmers removed dead fish daily, but only few recorded these numbers. The PM during the first 2 wk was less than $10 \%$. Overall PM was 20 to 


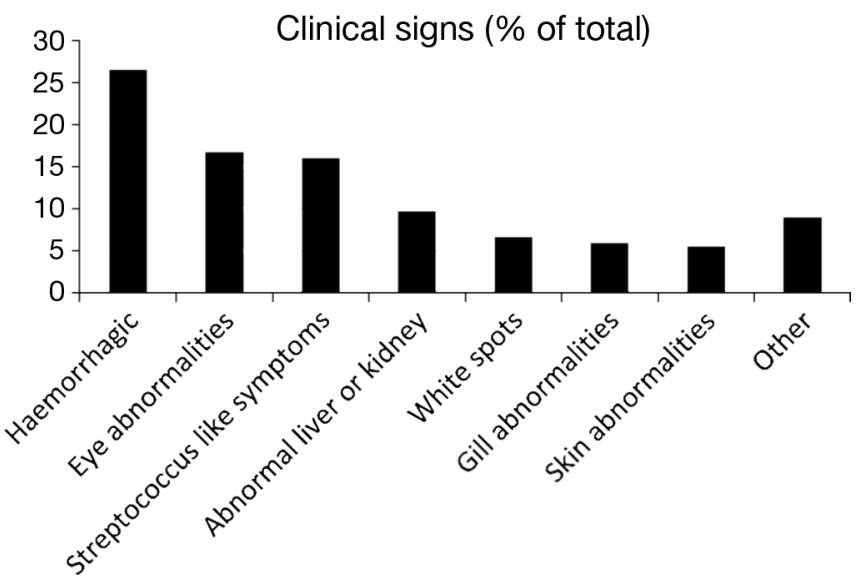

Fig. 5. Most common clinical signs in farmed red tilapia (Oreochromis spp.) according to the interviewed farmers ( $\mathrm{n}=193$ respondents)

$30 \%$, with a maximum of $70 \%$ reported by 1 farmer. Farmers were usually not aware of the cause of death, and rarely sent fish to a diagnostic laboratory for testing. Farmers attributed ROM and RIM mainly to disease and pollution (for ROM: 43 and $41 \%$ of total, respectively; for RIM: 33 and $17 \%$ of total) as well as to stress (33\%) in the case of RIM. The majority of farmers sold dead fish as food to farmers of other fish species such as African catfish Clarias gariepinus, hybrid catfish C. gariepinus $\times$ C. macrocephalus, and freshwater silver pomfret Colossoma brachypomum.

The most common diseases/clinical signs/lesions that farmers reported in the questionnaire were, in de-

Table 1. Factor scores describing the category 'site/employment,' based on 178 observations

\begin{tabular}{|lllcc|}
\hline Factor & Description & Mainly influenced by & $\begin{array}{c}\text { Percentage } \\
\text { variation } \\
\text { described }\end{array}$ & $\begin{array}{c}\text { Median } \\
\text { (min., max.) }\end{array}$ \\
\hline 1 & Water quality & $\begin{array}{l}\text { Density of fish in cage, } \\
\text { distance to nearest city }\end{array}$ & 23 & $\begin{array}{c}-2.4 \\
(-5.2,0.7) \\
1.8\end{array}$ \\
2 & Size of farm & $\begin{array}{l}\text { Number of employees, } \\
\text { number of cages in use }\end{array}$ & 21 & $(0.005,10.8)$ \\
\hline
\end{tabular}

Table 2. Rotated factor loadings and unique variances for 'site/employment'

\begin{tabular}{|lrrc|}
\hline Variable & $\begin{array}{c}\text { Factor } \\
1\end{array}$ & $\begin{array}{c}\text { Factor } \\
2\end{array}$ & $\begin{array}{c}\text { Unique- } \\
\text { ness }\end{array}$ \\
\hline Number of cages in use & -0.11 & 0.73 & 0.36 \\
Years site operational & 0.14 & 0.02 & 0.34 \\
Employees on site (yes/no) & 0.17 & 0.85 & 0.24 \\
Number of fish per cage $/ \mathrm{m}^{3}$ volume in cage & -0.82 & -0.09 & 0.32 \\
Closest tilapia cage upstream $(\mathrm{m})$ & -0.07 & 0.10 & 0.55 \\
Distance to closest city $(\mathrm{km})$ & 0.81 & 0.02 & 0.33 \\
\hline
\end{tabular}

scending order, hemorrhages, abnormal eyes, Streptococcus-like clinical signs, abnormal liver or kidney, white spots (internally or externally), and gill and skin abnormalities (Fig. 5). We pooled these disease/ clinical sign/lesion categories out of many answers that farmers gave to an open question.

\section{Associations between 'overall PM' and predictors}

For the group 'general farmer,' 4 dichotomous predictors were combined into 2 predictors to represent the scores of the first 2 factors. The first predictor was a combination of 'unconsumed fish are food for dogs $(\mathrm{y} / \mathrm{n})^{\prime}$ and 'discard unconsumed fish in river $(\mathrm{y} / \mathrm{n})$. ' The second predictor was a combination of 'consume fish from site $(\mathrm{y} / \mathrm{n})$ ' and 'consume fish caught within $500 \mathrm{~m}$ from site $(\mathrm{y} / \mathrm{n}))^{\prime}$ These predictors each consisted of 4 groups (yy, yn, ny, nn) out of the 2 dichotomous predictors they represented). For the group 'site/employment,' the first 2 factors scored were used to represent the group (Tables $1 \& 2$ ). The final set of predictors consisted of $\leq 3$ predictors in each of the 8 groups (indicated with '*' in Supplement Tables S1 \& S2).

Overall PM (Fig. 5) was affected by province, age of farmers, anticipated main reason for PM in the first $2 \mathrm{wk}$, most common market for the fish, and whether farmers recorded stocking information (Table 3). By province, overall PM was highest for farmers in An Giang $(36 \%)$, and lowest for farmers in Ben Tre $(24 \%$; $<0.01)$. By age of farmer, overall PM was higher for younger farmers than for older farmers $(p=0.01)$. Overall PM was not different between farmers who designated different ROMs, but was different for farmers who designated different RIMs ( $p=$ 0.03). Overall PM was lower for farmers who perceived disease to be the main reason for mortality within the first $2 \mathrm{wk}$, compared to farmers who perceived pollution or 'other' to be the main reason, but there was no significant difference between these reasons $(\mathrm{p}<0.05)$ with adjusted pairwise comparisons. Farmers for whom the Mekong Delta was the main market for their harvested fish scored lower overall PM than farmers for whom the main market was outside the Mekong Delta $(p=0.02)$. Farmers who recorded stocking information scored lower 
overall PMs than farmers who did not record this ( $p=0.01)$. Results of interval regression gave similar estimates.

\section{Practices potentially influencing introduction and spread of pathogens}

Live fish movements to and from the farm reflected stocking of fish at the start of the production cycle, fish movements between farms throughout the production cycle, and harvesting of fish at the end of the production cycle (Fig. 6a). Dead fish movement to a farm occurred via human consumption of fish that were caught or purchased off farm. This could be a route of introduction of pathogens to the farm if farmers feed unconsumed fish to the cultured fish. Dead fish movement from a farm occurred through cultured red tilapia (mortalities or partially consumed by farmers) discarded in the river or sold as food to other fish farmers (Fig. 6b). Environmental parameters that could potentially affect transmission of pathogens to and from a farm are short upstream and downstream distances to other tilapia cages (median distances of 20 and $10 \mathrm{~m}$, respectively). Proximity to upstream cities may affect water quality and hence disease susceptibility (Fig. 6c). Mechanical transmission and biosecurity practices were identified as
Table 3. Results of the multivariable linear model for overall perceived mortality (PM). Different superscripts within predictors indicate significant differences (Bonferroni adjusted)

\begin{tabular}{|c|c|c|c|c|c|}
\hline \multirow[t]{2}{*}{ Predictor } & \multicolumn{2}{|c|}{ Predicted PM (\%) } & \multirow{2}{*}{$\begin{array}{c}\text { Coeffi- } \\
\text { cient }\end{array}$} & \multirow[t]{2}{*}{$\mathrm{SE}$} & \multirow[t]{2}{*}{$\mathrm{p}$} \\
\hline & Mean & $95 \% \mathrm{CI}$ & & & \\
\hline \multicolumn{5}{|l|}{ Province } & $<0.01$ \\
\hline An Giang (AG) & $36^{\mathrm{b}}$ & $33-39$ & Ref. & Ref. & \\
\hline Vinh Long (VL) & $30^{\mathrm{ab}}$ & $26-33$ & -6.4 & 2.4 & \\
\hline Dong Thap (DT) & $32^{\mathrm{b}}$ & $28-35$ & -4.3 & 2.2 & \\
\hline Ben Tre (BT) & $24^{\mathrm{a}}$ & $21-27$ & -12.4 & 2.2 & \\
\hline Farmer's year of birth & na & na & 0.2 & 0.08 & $<0.01$ \\
\hline \multicolumn{5}{|c|}{ Main reason for mortality in the first 2 weeks post stocking (RIM) } & 0.03 \\
\hline Disease & $29^{\mathrm{a}}$ & $26-31$ & Ref. & Ref. & \\
\hline Temperature fluctuations & $33^{\mathrm{a}}$ & $28-37$ & 3.5 & 3.1 & \\
\hline Stress & $28^{\mathrm{a}}$ & $25-31$ & -0.8 & 2.0 & \\
\hline Pollution & $32^{\mathrm{a}}$ & $29-37$ & 4.1 & 2.4 & \\
\hline Other & $37^{\mathrm{a}}$ & $31-42$ & 7.8 & 3.1 & \\
\hline \multicolumn{5}{|c|}{ Most common market for the fish is the Mekong Delta } & 0.02 \\
\hline No & 32 & $30-34$ & Ref. & Ref. & \\
\hline Yes & 28 & $26-30$ & -3.9 & 1.6 & \\
\hline \multicolumn{5}{|c|}{ Stocking information recorded } & 0.01 \\
\hline No & 31 & $29-33$ & Ref. & Ref. & \\
\hline Yes & 26 & $23-30$ & -4.9 & 1.9 & \\
\hline Intercept & na & na & -405.5 & 161.8 & 0.01 \\
\hline
\end{tabular}

lack of treating fish before stocking, feed storage, lack of disinfectants used by harvesters before entering a farm, sharing equipment between sites directly or indirectly (via harvesters), and harvesters visiting different farms on the same day. In addition, persistence of pathogens on the farm could be affected by lack of cleaning nets before stocking, short duration of fallow period, and mixing of fish from different cages (Fig. 6d).

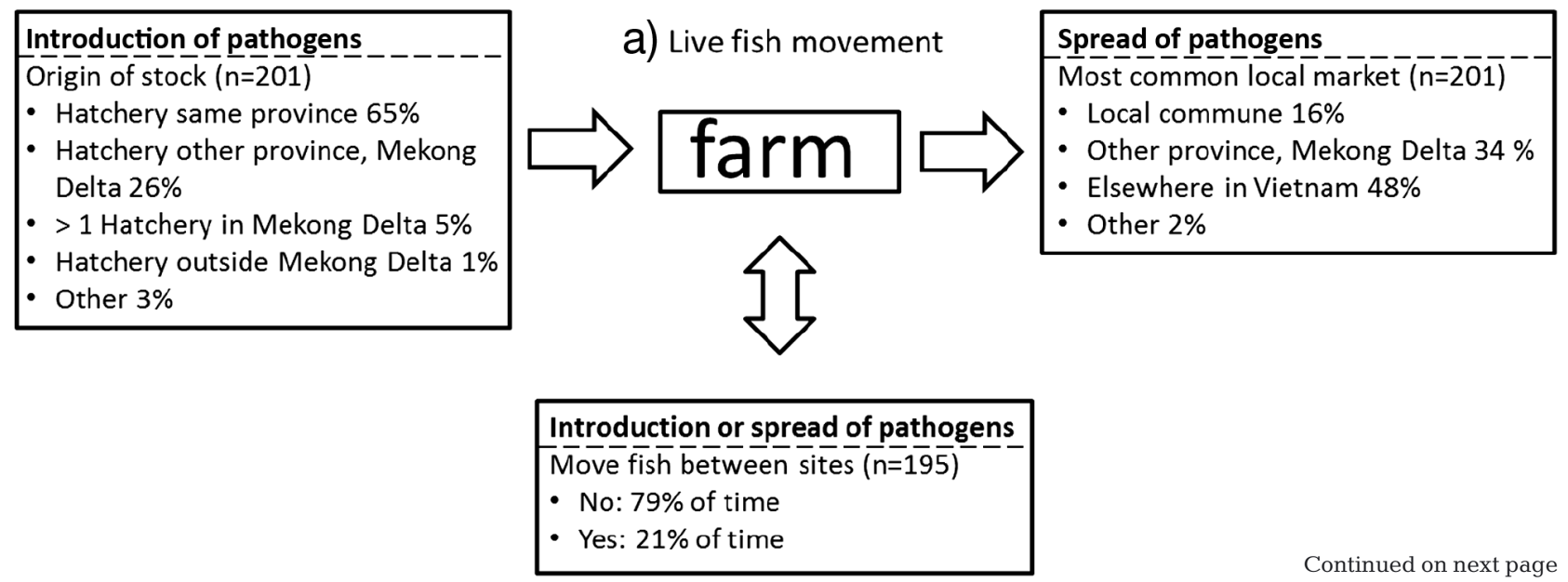

Fig. 6. Farmers' answers to the questionnaires for practices potentially influencing introduction or spreading of pathogens from or to a farm, or maintaining disease within the farm, by (a) live fish movement, (b) dead and harvested fish movement,

(c) environmental factors, and (d) mechanical transmission and biosecurity practices 
Introduction of pathogens

Consume fish caught within $\overline{50} \overline{\mathrm{m}} \overline{\mathrm{m}}$

from site $(n=201)$

- Weekly $45 \%$

- Less than weekly $25 \%$

- Never $29 \%$

Consume fish bought at local

market $(n=201)$

- Weekly $49 \%$

- Less than weekly $33 \%$

- Never $18 \%$

Discard unconsumed $\overline{\text { fish }} \overline{\text { as }} \overline{\text { food }} \overline{\text { for }}$

- No $94 \%$

- Yes 6\% fish in cages $(n=201)$

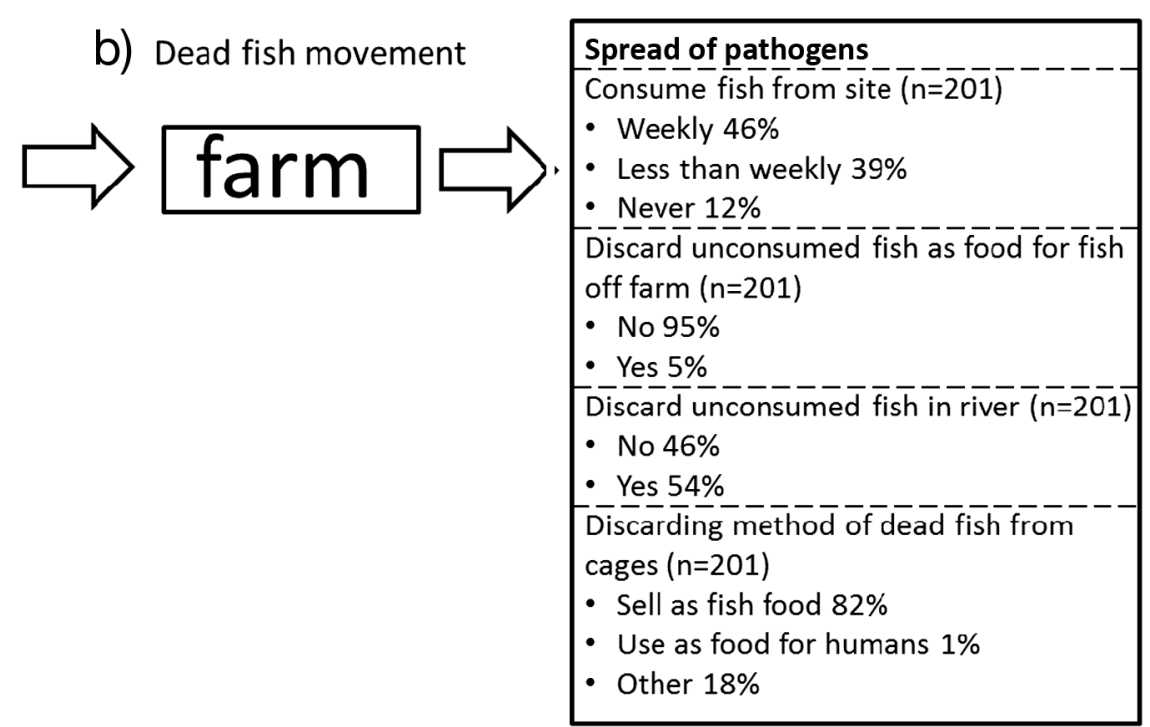

C) Environmental parameters

Closest tilapia cage upstream

( $\mathrm{n}=193$ )

- Median: $20 \mathrm{~m}$

Distance to closest city upstream

$(\mathrm{n}=193)$

- Median: 4 km

\begin{tabular}{|l|}
\hline Introduction of pathogens \\
\hline Treat fish before stocking \\
( $n=200)$ \\
- No $18 \%$ \\
- Yes $82 \%$ \\
Type of feed ( $\mathrm{n}=2 \mathrm{0}-1)$ \\
- Pellet $99 \%$ \\
- Fish from fisherman $1 \%$ \\
- Dead fish from other farms $1 \%$ \\
- Harvester uses disinfectants \\
( $n=200)$ \\
- Never $74 \%$ \\
- $\geq 80 \%$ of time $21 \%$ \\
- Other $5 \%$ \\
\hline
\end{tabular}

d) Mechanical transmission and biosecurity practices

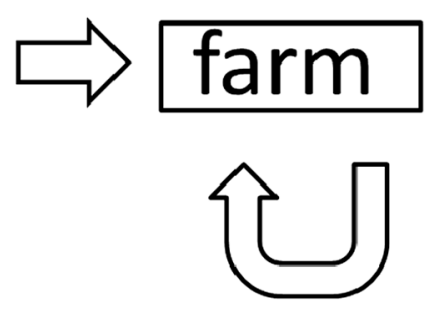

\section{Persistence}

Mix fish stocked at different times

$(n=200)$

- Yes $21 \%$

- No $79 \%$

Duration of fallow period $(\mathrm{n}=\overline{200})$

- $1-7$ days $75 \%$

- $1-2$ weeks $18 \%$

- Other $7 \%$

Clean nets before stocking $\overline{(\mathrm{n}=20 \overline{0})}$

- $\geq 80 \%$ of time $87 \%$

- Never $3 \%$

- Other $10 \%$

After partial harvest, mix remaining

fish with other cages $(n=114)$

- $\geq 80 \%$ of time $24 \%$

- Never $67 \%$

- Other $9 \%$
Introduction or spread of pathogens If $>1$ site, farmer uses equipment on both $(n=69)$

- No $41 \%$

- Yes $59 \%$

Origin of harvest nets ( $\mathrm{n}=200)$

- Always stay on site $49 \%$

- Travel with harvester $42 \%$

- Other $9 \%$

Harvester visits multiple farms on

the same day $(n=199)$

- Never $12 \%$

- $\geq 80 \%$ of time $36 \%$

- Other $62 \%$

\begin{tabular}{|l|}
\hline Introduction, spread or \\
persistence of pathogens \\
\hline Other animals on farm $(n=201)$ \\
- None $59 \%$ \\
- Dogs $30 \%$ \\
- Mice and rats $3 \%$ \\
- Other $8 \%$ \\
\hline
\end{tabular}

Fig. 6 (continued) 


\section{DISCUSSION}

The first objective of this study, to describe smallscale red tilapia production systems in the Mekong Delta, Vietnam, was intended to develop fundamental knowledge of the production systems, especially focused on fish health. This provided a basis for the second objective, which was to quantify mortality and investigate how production factors are related to mortality. The context that informed the approach and structure of our surveys was the potential for infectious disease incursion. Should an outbreak investigation be necessary or a risk-based surveillance program be considered, factors representing higher risk of pathogen introduction or spread between farms would inform the most efficient design approaches. Describing these processes was our third objective.

\section{Associations between 'overall PM' and predictors}

The study used PM reported by the farmer as an outcome. PM served as a substitute for recorded mortality, because the latter was not available. Although PM cannot replace recordings of mortality, we believe that PM is a sound approximation because the experience-based farmers' knowledge is often valuable (Stuiver et al. 2004).

Within the category 'mortality,' the only variable affecting overall PM was the reported RIM. Disease and stress may arise due to suboptimal transport and handling prior to stocking events, leading to early grow-out periods with more compromised and stressed fish. Hence, disease and stress shortly after stocking are events related more to the stocking conditions than to the remaining grow-out period. The other listed RIMs, viz. pollution and temperature fluctuations, are factors that affect the fish throughout the grow-out period and may therefore contribute more to overall PM. Perhaps a sign of the complexity of these systems, ROM was not associated with reasons reported by farmers for ROM or the magnitude of farmers' initial PM.

From the category 'general and farmer,' 2 variables affected overall PM. First, there was a significant difference between provinces. Geographically, PM increased in provinces farther downstream in the river system, and the difference between the extremes was significant. This could be a result of the potential accumulation of contaminants affecting water quality, or local factors such as method of food delivery to the farm. However, our study design did not enable such differentiation. Second, overall PM was higher for younger farmers, which may imply that older farmers benefit from their experience, but may also reflect age-related perceptions. Studies on other farming practices show that biographical aspects, such as the effects of age or experience of farmers, are diffuse and variable (reviewed by Rougoor et al. 1998).

None of the variables in the category 'human consumption of fish' affected overall PM, although some of these practices may affect pathogen introduction or spread, as will be discussed later.

For the category 'site and employment,' neither the factors describing water quality or farm size affected overall PM. This was unexpected for 2 reasons. First, stocking density is reported to affect stress levels of tilapia (El-Sayed 2002). Second, larger farms are characterized by close proximity to greater numbers of fish, which may lead to greater potential for exposure to pathogens and disease (Salama \& Murray 2011). Perhaps relative to other circumstances, differences between farms were too small to affect overall PM.

In the category 'fallow and stocking,' there were only slight differences between farmers, because more than half of the farmers' answers were $100 \%$ identical, and in most remaining cases, $90 \%$ the same, especially after similar answers within a question were grouped. Even if they were important contributors, the symmetry of responses within this category would naturally negate the ability to detect associations of variables with overall PM.

None of the variables in the category 'between stocking and harvest' affected overall PM. Feeding methods were the same for most farmers, so there would not be any detectable differences in effects. However, there were differences between farmers in mixing of fish between cages or farms, which may affect pathogen introduction or spread to or from a farm (see below).

In the category 'harvest,' farmers who sold their products within the Mekong Delta expected lower overall mortality than farmers who sold their product elsewhere in Vietnam. Perhaps farmers who sell their fish outside of the Mekong Delta have less control over their harvest schedule and, hence, experience more mortality during any harvest delays. However, factors affecting farmers' decisions were beyond the scope of this study, but the variable 'duration of grow-out period' did not affect mortality.

In the last category, 'record keeping,' overall PM for farmers who recorded stocking information was lower than for farmers who did not record this information. This may reflect a closer attention to detail 
that is associated with timely treatment or change of practice, and consequently lower mortality rates. Whether or not farmers recorded mortality or harvesting numbers had no effect on overall PM. This may be counterintuitive, because these are events that occur during and after the production cycle and are affected by events that happen during the production cycle.

There could be several explanations for the fact that few variables affected overall PM. First, the variation between farms in the study population may have been too small to account for measurable differences within the method we used, as most farmers had similar husbandry strategies. When there is considerable difference between sectors, this method can differentiate between sub-sectors (Joffre \& Bosma 2009). Second, the outcome variable, PM, was an estimate made by farmers that we could not verify because too few farmers recorded information on stocking or harvesting numbers. We asked farmers to provide estimates in intervals of $10 \%(0-10$, up to 91-100\%) because more precise estimates were not considered meaningful. Third, mortality is a nonspecific outcome that is the result of complex interactions involving environment, fish hosts, and pathogens. Even though farmers do not test their fish for pathogens, $17 \%$ of farmers observed Streptococcuslike clinical signs (Fig. 5). The bacterium S. agalactiae has been isolated from red tilapia in the Mekong Delta (Oanh \& Phuong 2011) and is known to cause mortality in red tilapia (Abuseliana et al. 2010). It could therefore be that local differences in pathogen burden, in particular $S$. agalactiae, are the basis of variation in overall PM. Although not unexpected, an important finding of this study was the fact that farmers do not record mortality or other variables, making detection and investigation of an infectious disease outbreak very difficult and laborious.

\section{Practices potentially influencing introduction and spread of pathogens}

Our third objective was to describe practices that may influence introduction and spread of pathogens to and from farms. A valuable next step would be to quantify these risks, but this was beyond the scope of our study.

Live fish movement is an important factor associated with the spread of pathogens to new areas in aquaculture (Subasinghe \& Phillips 2002). Most red tilapia farmers received their fish from 1 hatchery in the same province, and all farmers received fish from hatcheries within the Mekong Delta. During the production cycle, most farmers did not move live fish between sites, thus avoiding exchange of pathogens in this manner. Therefore, this pathway appears to pose a small risk for introduction of non-endemic pathogens.

There were movements of dead and harvested fish from farms. Most dead fish were collected to serve as food for other aquaculture sectors, a practice that may spread pathogens. All farmers lived on their farms and, by purchasing fish from local markets or catching them in rivers, they expose their farmed fish to externally-sourced fish carcasses and, possibly, pathogens. However, only very few farmers fed unconsumed fish parts to their tilapia, and because the chance of mixing between red tilapia and consumption fish is small, the risk of pathogen introduction through dead fish is likely substantially reduced. Half of the farmers discarded unconsumed fish in the river, where pathogens may be transmitted via water to downstream cages.

There was also a risk of infection through environmental parameters. Due to the close proximity between farms, there may be a higher risk of pathogen spread to farms downriver, depending on the capacity of pathogens to transmit through water or fomites. Also, wild fish represent a likely source of pathogen transmission between farms, but little is known about this potential in the Mekong. Boat traffic and proximity of farms are important risk factors for disease in aquaculture (McClure et al. 2005, Stene et al. 2014). In the Mekong Delta, boat traffic volumes are high on the river but occur primarily in the main channel while farms are located along the shores and in tributaries or secondary channels. Boat traffic in close proximity to sites involves farmers, visitors to the farms, and industry-based movements for food delivery and daily collection of mortalities, and could therefore be an important mechanism for pathogen spread. Overall, we consider this risk to be substantial.

There were also mechanical transmission and biosecurity risks. Predators or scavengers rarely occur on these farms, according to the farmers, and so are of little concern for pathogen exposure. Sharing of equipment between multiple sites owned by the same farmer, or between farms through harvesters that do not disinfect, was identified as common practice. Fallow periods can reduce pathogen load in aquaculture (Werkman et al. 2011), and surveyed farmers reported the use of fallowing, but only at the cage level and usually for fewer than $7 \mathrm{~d}$. For disease control at the site or zone levels, a longer fallow period may be more effective, depending on the 
pathogen and other measures. However, it is not practical to suggest larger-scale fallowing without more knowledge about the effect such a practice would have on both disease control and economics. Concerning fish food, tilapia received primarily pelleted feed, which is generally accepted as low risk for pathogen introduction. None of the farmers reported feeding dead (red) tilapia purchased from surrounding farms, which would pose a high risk. In general we consider this risk mild, although there are opportunities for simple changes in management strategies, such as increasing fallow periods, that may lead to significant improvements.

\section{Disease detection and investigation opportunities}

Most of the farmers in the study did not record information on feed, mortality, or other parameters, which limits estimations of feed conversion ratio, yield, and other production measures that are needed to describe the industry better. There was little involvement of health professionals or diagnostic laboratories for disease testing, which was consistent with another survey on small-scale fish farming in the area (Jeney et al. 2002). Even though most rural, small-scale farmers have, in general, little knowledge of health management (Subasinghe \& Phillips 2002), the more developed and intensive aquaculture industries in the area, like the striped catfish industry, record production information as a common practice (Phuong et al. 2011), which seems to be a characteristic of larger industries.

The Vietnamese government regulates freshwater fish cage culture for food safety and environment protection. Regulations include frequent cleaning of net cages, applying treatment early, applying treatment with approved chemicals only, applying antibiotics only when causative agents are known, applying treatments by producers or experienced technicians, recording of treatments, monitoring of water quality and management strategies, and banning movement of cages with diseased fish (Ministry of Agriculture \& Rural Development 2015). If we compare these to practices that we observed as potentially important for the spread of pathogens, regulations should also consider distances between farms and equipment sharing or disinfection practices. Farmers' adoption of best practices would require an education initiative. Regulations on minimum distance between farms would only be successful if adopted by all farms, and therefore requires an industry-wide regulatory approach. Although such recommendations would be based on best practice principles, they may prove too great a financial burden for the theoretical reduction in risk potential. More evidence-based approaches, perhaps employing clinical trials, are needed for further justification.

The red tilapia industry has grown in scale over the past decade, and more families depend on this industry for their livelihoods. Its size and intensity in the area creates a concern that an infectious disease, once introduced, could spread with few constraints and cause large economic impacts. The lack of record systems or means to diagnose emerging diseases will seriously compromise the possibility of early response and mitigation. Standardized records for information are useful for detection of patterns of spread, such as daily mortality and clinical signs, and possibly the use of various antimicrobial treatments, and could serve as an early warning system for disease. Such awareness would contribute to earlier responses to disease outbreaks and antimicrobial resistance, and reduce overall economic losses.

Many similarities exist between terrestrial and aquatic farmers and, within aquaculture, between the different sectors of the industry. Lessons learned in one sector can help resolve problems in another sector (Baldock 2002). For example, better husbandry practices helped improve health management of striped catfish in the Mekong Delta (Phuong et al. 2011), and best aquaculture practices have been developed for tilapia by the Global Aquaculture Alliance (www. gaalliance.org) for certification purposes (Jory 2011). Combining knowledge of the red tilapia sector with recommendations of husbandry practices developed by such organizations could be adapted for use by small-scale farmers in the Mekong Delta. Currently, certification is not of interest to the farmers in our survey, as they mainly produce for local markets. There are local markets that require good aquaculture practice as a standard (VASEP 2012), but demand through such channels is relatively small. This situation may change as more local markets impose standards, or farmers expand to foreign markets. Aside from export markets, authorities can also have a huge impact on the development of a sector. The striped catfish and shrimp sectors in Vietnam initially grew quickly in the absence of environmental, food safety, and certification restrictions (Hishamunda et al. 2009), and regulations were developed at later stages to improve these industries with respect to production mechanisms, pollution, and antibiotic usage. Such an experience may provide a useful example for the developing tilapia sector on which to base their expansion and sustainability plans. 


\section{CONCLUSION}

This pilot study had a limited scope of investigation of mortality trends or their factors. It does provide a basic understanding of red tilapia aquaculture management in the Mekong Delta, and may inform the design of future disease detection and risk identification studies. In addition, this study revealed few differences in management factors across farms and only small effects on expected mortality, indicating that there is relatively little diversity within the system and that pathogen transmission risk is shared across all farms. Should a transmissible pathogen be introduced to one farm, the shared risk across most of the industry and interaction with other aquatic industries might have major economic consequences.

In the small-scale red tilapia production systems, average overall PM was within limits for small-scale aquaculture practices, and only a few of the characteristics observed, such as age of the farmer and recording stocking information, had an effect on overall PM. This study also shows potential routes for introduction and spread of pathogens, which are important in the event of disease outbreaks, such as the close proximity between farms. Further research on mortality, using quantitative observations of mortalities, is needed to inform improved health management and its effect on emerging or endemic disease trends.

Acknowledgements. We are grateful for the kind cooperation of farmers. We thank students of the College of Aquaculture and Fisheries, Can Tho University, for their contribution. This research was undertaken thanks to funding from the Canada Excellence Research Chairs program and InnovPEI. We thank William Chalmers for editorial assistance with the manuscript.

\section{LITERATURE CITED}

Abdelhadi YM (2011) Tilapia: from the Nile to the world. J Agric Sci Technol 5:251-255

Abuseliana A, Daud H, Aziz SA, Bejo SK, Alsaid M (2010) Streptococcus agalactiae the etiological agent of mass mortality in farmed red tilapia (Oreochromis sp.). J Anim Vet Adv 9:2640-2646

Arthur JR, Phillips MJ, Subasinghe RP, Reantaso M, MacRae I (eds) (2002) Primary aquatic animal health care in rural, small-scale, aquaculture development. FAO Fish Tech Pap 406. FAO, Rome

Baldock C (2002) Health management issues in the rural livestock sector: useful lessons for consideration when formulating programmes on health management in rural, small-scale aquaculture for livelihood. In: Arthur JR, Phillips M, Subasinghe RP, Reantaso M, MacRae I (eds) Primary aquatic animal health care in rural, small- scale, aquaculture development. FAO Fish Tech Pap 406. FAO, Rome, p 7-19

* Boklund A, Alban L, Mortensen S, Houe H (2004) Biosecurity in 116 Danish fattening swineherds: descriptive results and factor analysis. Prev Vet Med 66:49-62

* Bondad-Reantaso MG, Subasinghe RP, Arthur JR, Ogawa K and others (2005) Disease and health management in Asian aquaculture. Vet Parasitol 132:249-272

De Silva SS, Phillips MJ (2007) A review of cage aquaculture: Asia (excluding China). In: Soto D, Arthur JR (eds) Cage aquaculture - regional reviews and global overview. FAO Fish Tech Pap 498. FAO, Rome, p 18-48

* De Silva SS, Phuong NT (2011) Striped catfish farming in the Mekong Delta, Vietnam: a tumultuous path to a global success. Rev Aquacult 3:45-73

El-Sayed AFM (2002) Effects of stocking density and feeding levels on growth and feed efficiency of Nile tilapia (Oreochromis niloticus L.) fry. Aquacult Res 33:621-626

El-Sayed AFM (2006) Tilapia culture. CABI Publishers, Wallingford

FAO (Food and Agriculture Organization of the United Nations) (2014) The state of world fisheries and aquaculture 2014. FAO, Rome

Gupta MV, Acosta BO (2004) A review of global tilapia farming practices. Aquacult Asia Mag 9:7-12

*Hishamunda N, Ridler NB, Bueno P, Yap WG (2009) Commercial aquaculture in Southeast Asia: some policy lessons. Food Policy 34:102-107

Hung P (2010) Low-value freshwater fish market in the south central Vietnam, a case study from Khanh Hoa Province. Aquacult Asia Mag 15:22-25

Jeney Z, Hao NV, Trong QT, Mui NT, Hong PTB, Thanh NM, MacRae IH (2002) Preliminary results of the fish health survey in rural aquaculture of Tien Giang Province, Vietnam. In: Arthur JR, Phillips MJ, Subasinghe RP, Reantaso MB, MacRae IH (eds) Primary aquatic animal health care in rural, small-scale, aquaculture development. FAO Fish Tech Pap 406. FAO, Rome, p 323-332

Joffre OM, Bosma RH (2009) Typology of shrimp farming in Bac Lieu Province, Mekong Delta, using multivariate statistics. Agric Ecosyst Environ 132:153-159

Jory DE (2011) Best aquaculture practices standards for the tilapia industry: certification for greater sustainability. In: 9th International Symposium on Tilapia in Aquaculture, April 2011, Shanghai, China

Kolenikov S, Angeles G (2004) The use of discrete data in PCA: theory, simulations, and applications to socioeconomic indices. Carolina Population Center, University of North Carolina, Chapel Hill, NC

Lauritsen JM, Bruus M (2016) EpiData Entry 3.1. A comprehensive tool for validated entry and documentation of data. The EpiData Association, Odense. www.epidata.dk (accessed 4 April 2016)

* Leaño EM, Mohan C (2012) Early mortality syndrome threatens Asia's shrimp farms. Global Aquacult Advocate 38-39

Lightner DV, Redman RM, Pantoja CR, Noble BL, Nunan LM, Tran L (2013) Emergence of a new disease in Southeast Asian shrimp farms. World Aquaculture Society Meetings abstract 2013 Nashville, TN. www.was.org/meetings/ ShowAbstract.aspx?Id=28455 (accessed 4 Apr 2016)

Manly BF (2004) Multivariate statistical methods: a primer, 3rd edn. CRC Press, New York, NY

*McClure CA, Hammell KL, Dohoo IR (2005) Risk factors for outbreaks of infectious salmon anemia in farmed Atlantic salmon, Salmo salar. Prev Vet Med 72:263-280 
Ministry of Agriculture \& Rural Development (2015) National technical regulation on freshwater fish cage culture - conditions for food safety and environmental protection. MARD, Ha Noi

Nguyen NBT, Vo PL (2011) Better management practices for tilapia cage farming in Tien Giang, Vietnam. Aquacult Asia Mag 16:16-20

Nguyen VS, Tu VB (2013) Aquaculture market and development strategy: the case of Pangasius in the Mekong Delta, Vietnam. J Econ Dev 13:74-96

Oanh DTH, Phuong NT (2011) Isolation and characterization of Streptococcus agalactiae from red tilapia cultured in the Mekong delta of Vietnam. In: Proc 9th International Symposium on Tilapia in Aquaculture, April 2011, p 30

Oidtmann B, Crane C, Thrush M, Hill B, Peeler E (2011) Ranking freshwater fish farms for the risk of pathogen introduction and spread. Prev Vet Med 102:329-340

Phuong NT, Oanh DTH (2010) Striped catfish aquaculture in Vietnam: a decade of unprecedented development. In: De Silva SS, Davy FB (eds) Success stories in Asian aquaculture. Springer, Dordrecht, p 131-147

Phuong NP, Hao NV, Tam BM, Lam PT and others (2011) Better management practices for striped catfish (tra) farming in the Mekong delta, Viet Nam, version 3.0, May 2011. Vietnam Ministry of Agriculture and Rural Development, Ha Noi

Romana-Eguia MRR, Ikeda M, Basiao ZU, Taniguchi N (2004) Genetic diversity in farmed Asian Nile and red hybrid tilapia stocks evaluated from microsatellite and mitochondrial DNA analysis. Aquaculture 236:131-150

Rougoor CW, Trip G, Huirne RB, Renkema JA (1998) How to define and study farmers' management capacity: theory and use in agricultural economics. Agric Econ 18:261-272

Salama NKG, Murray AG (2011) Farm size as a factor in hydrodynamic transmission of pathogens in aquaculture fish production. Aquacult Environ Interact 2:61-74

Silva SS, Nguyen TT, Abery NW, Amarasinghe US (2006) An evaluation of the role and impacts of alien finfish in Asian inland aquaculture. Aquacult Res 37:1-17

StataCorp (2015) Stata statistical software: release 14. StataCorp LP, College Station, TX

Editorial responsibility: Lori Gustafson,

Fort Collins, Colorado, USA
Stene A, Viljugrein H, Yndestad H, Tavornpanich S, Skjerve E (2014) Transmission dynamics of pancreas disease (PD) in a Norwegian fjord: aspects of water transport, contact networks and infection pressure among salmon farms. J Fish Dis 37:123-134

Stuiver M, Leeuwis C, van der Ploeg JD (2004) The power of experience: farmers' knowledge and sustainable innovations in agriculture. In: Wiskerske JSC, Van der Ploeg JD (eds) Seeds of transition: essays on novelty production, niches, and regimes in agriculture. Royal van Gorcum, Assen, p 93-117

* Subasinghe RP (2005) Epidemiological approach to aquatic animal health management: opportunities and challenges for developing countries to increase aquatic production through aquaculture. Prev Vet Med 67:117-124

Subasinghe RP, Phillips M (2002) Aquatic animal health management: opportunities and challenges for rural, small-scale aquaculture and enhanced-fisheries development: workshop introductory remarks. In: Arthur JR, Phillips M, Subasinghe RP, Reantaso M, MacRae I (eds) Primary aquatic animal health care in rural, small-scale, aquaculture development. FAO Fish Tech Pap 406. FAO, Rome, p 1-5

VASEP (Vietnam Association of Seafood Exporters and Producers) (2012) Metro Cash \& Carry Vietnam to set up Metro Requirements for fishery industries. http://vasep. com.vn/Tin-Tuc/53_2865/Metro-Cash-Carry-Viet-NamXay-dung-tieu-chuan-Metro-Requirements-ve-thuc-hanh -nong-nghiep-tot-cho-nganh-thuy-san.htm (accessed 22 December 2016)

VASEP (2016a) An overview of Vietnam fishery sector. http: //vasep.com.vn/1192/OneContent/tong-quan-nganh.htm (accessed 22 December 2016)

VASEP (2016b) Tilapia exports set to shoot up in years ahead: VASEP. http://vietnam.vnanet.vn/english/tilapiaexports-set-to-shoot-up-in-years-ahead-vasep/258011. html (accessed 9 February 2016)

*Werkman M, Green DM, Murray AG, Turnbull JF (2011) The effectiveness of fallowing strategies in disease control in salmon aquaculture assessed with an SIS model. Prev Vet Med 98:64-73

Submitted: September 19, 2016; Accepted: February 14, 2017 Proofs received from author(s): April 9, 2017 